\title{
A Retrospective Review: Vaginal versus Abdominal Hysterectomy for Benign Gynecological Diseases in a Tertiary Canter
}

\author{
Lujain Bukhari' ${ }^{1}$, Ayman A. Bukhari' ${ }^{1}$, Omar F. Albakri' ${ }^{1}$, Arwa F. Alshamrani', Walaa E. Alahmadi ${ }^{2}$ \\ Hassan S. O. Abduljabbar ${ }^{*}$ \\ ${ }^{1}$ Obstetrics and Gynecology Department, King Abdulaziz University Hospital, Jeddah, Saudi Arabia \\ ${ }^{2}$ Biochemistry Department, King Abdulaziz University Hospital, Jeddah, Saudi Arabia \\ ${ }^{3}$ Department of Obstetrics \& Gynecology, Medical College, King Abdulaziz University, Jeddah, Saudi Arabia \\ Email:1ujainbukhari@gmail.com, bukhari84@hotmail.com, arwa_sh10@hotmail.com, Walaa.alahmadi@gmail.com, \\ *profaj17@yahoo.com
}

How to cite this paper: Bukhari, L., Bukhari, A.A., Albakri, O.F., Alshamrani, A.F., Alahmadi, W.E. and Abduljabbar, H.S.O. (2016) A Retrospective Review: Vaginal versus Abdominal Hysterectomy for Benign Gynecological Diseases in a Tertiary Canter. Open Journal of Obstetrics and Gynecology, 6, 761-768.

http://dx.doi.org/10.4236/ojog.2016.612094

Received: October 8, 2016

Accepted: November 21, 2016

Published: November 24, 2016

Copyright $\odot 2016$ by authors and Scientific Research Publishing Inc. This work is licensed under the Creative Commons Attribution International License (CC BY 4.0).

http://creativecommons.org/licenses/by/4.0/

\begin{abstract}
The aims are to review respectively 229 cases of hysterectomy and to find the factor affecting the decision of vaginal hysterectomy. Data collected from medical charts include age, nationality, parity, menopause, history of Dilation and curettage. The following data were obtained: the clinical presentation and the indication for hysterectomy. Postoperative complication includes the estimated blood loss, the number of days in hospital and ICU admission recorded. The route of hysterectomy found that $187(82 \%)$ were abdominal and only $42(18 \%)$ were vaginal. Factors significantly associated with the choice of vaginal approach: age, parity, smaller uterine size and prolapse. Factors affecting the decision of vaginal hysterectomy for treatment of benign diseases are identified as follows: if the age is more than 35 years or if the women already reach menopause, the presenting symptoms are not vaginal bleeding but prolapsed uterus and uterine size is less than 12 weeks.
\end{abstract}

\section{Keywords}

Vaginal, Abdominal, Hysterectomy

\section{Introduction}

Hysterectomy is one of the commonest major procedures carried out on female patients. Hysterectomy is the ultimate treatment for many gynecological diseases especially in older patients or patients who completed their family. The annual estimation 
of hysterectomies performed is 600,000 in US and 40,000 in England [1]. By the age of 64 , about $40 \%$ of all women worldwide will have a hysterectomy, and it is mainly performed for improvement in symptomatology and quality of life. Vaginal hysterectomy $(\mathrm{VH})$ should be used in preference to the laparoscopic or abdominal approaches for benign indications as recommended by the American College of Obstetricians and Gynecologists (ACOG) [2].

This was announced following the publication of a recent meta-analysis from the Cochrane Collaboration, reporting that vaginal route has less postoperative pain and reduced recovery time [3].

Still, the rates of hysterectomies carried out vaginally are low. Nulliparity, previous abdominal surgery and the need of experience are reported as causes for favoring the abdominal approach by most surgeons [4]. In a systematic review done in 2014, it was reported that the most common approach used in hysterectomies was the abdominal approach except when the uterovaginal prolapse is the pathology involved [1].

In a 2005 local study, it showed that vaginal route was being used only for prolapse cases [5]. A previous study was done in our center on 2008 reported that the abdominal approach is more commonly used than vaginal [6]. In China, the vaginal approach is the most common method used overall [7]. On the other hand, abdominal hysterectomy $(\mathrm{AH})$ remains the main surgical route of hysterectomy for patients with uterine leiomyomas. There are limited data in our country reviewing factors influencing the selection of the route for hysterectomy and the incidence of complications after each in comparison to the literature.

The aim of this study was to evaluate the adherence to our practice of hysterectomy to the general guidelines, providing data that could be used for the future audit.

\section{Methods and Patients}

A retrospective medical charts review of all cases of hysterectomy performed at King Abdulaziz University Hospital (KAUH), it is a tertiary teaching hospital with a capacity of 850 beds Department of Obstetrics and Gynecology 180 beds, from January 2010 to May 2014, and ethical approval obtained from the ethical hospital committee.

Two hundred and twenty-nine cases had a hysterectomy. The data collected from medical record charts including: age in years, nationality (Saudi or Non-Saudi), parity, and also the past medical and surgical history and menopausal status. Their clinical presentation is as follows: vaginal bleeding, abdominal pain, abdominal swelling, and prolapsed.

The data recorded were indication for hysterectomy, estimated blood loss, postoperative complication, route of hysterectomy, type of anesthesia and number of days in the hospital as well as and the number of patients admitted to ICU.

Inclusion Criteria: 1) Patients admitted with a diagnosis of benign disease of the uterus, 2) for hysterectomy, 3) managed at KAUH.

Exclusion criteria: 1) hysterectomy done for malignant diseases, 2) during cesarean section, 3) laparoscopic hysterectomy, 4) cases transferred another facility, 5) or if their 
chart was incomplete.

The Statistical Package for the Social Sciences (PC SPSS) used to analyze data using different methods of statstical analysis to correlate between vaginal versus abdominal hysterectomy

The primary variables are hysterectomy for treatment of benign disease 0 for vaginal hystrectomy 1 for abdominal hysterectomy. Variables used age in years, nationality Saudi and non-Saudi, parity, menopause or not, past medical history, past surgical history, presenting symptom bleeding or otherwise, prolapse or otherwise, and utrine size less than $12 \mathrm{~cm}$ or larger $(\mathrm{sig}<0.05)$. Odds ratio and $95 \%$ Confidence Interval were used to present the results.

Authors have no conflict of interests, and the work was not supported, or funded by any drug company.

\section{Results}

Total number of cases of hysterectomy was 229 cases. The range of age is 25 to 84 years with a mean of $(51.9 \pm 9.5)$. The range of party was 0 to 14 with a mean $(4.1 \pm 3.4)$. Out of 229 patients, had the hysterectomy in the study period for benign conditions 187 (81.7\%) were the abdominal approach and $42(18.3 \%)$ were vaginal approach (Table 1$)$.

The indications for hysterectomy are illustrated in Table 2.

Out of the 99 patients with a diagnosis of a fibroid, 97 cases had the abdominal hysterectomy and only two cases done vaginally. From 36 cases done for uterine prolapse, the majority were performed vaginally in 30 (83\%), and abdominal approach used in

Table 1. Percentage of vaginal hysterectomy.

\begin{tabular}{ccc}
\hline Routs & Number & Percentage \\
\hline Vaginal hysterectomy & 42 & $18.3 \%$ \\
Abdominal hysterectomy & 187 & $81.7 \%$ \\
Total & 229 & $100 \%$ \\
\hline
\end{tabular}

Table 2. Indication for surgery.

\begin{tabular}{ccccc}
\hline Indication & Vaginal & Abdominal & Total & Percentage \\
\hline Uterine fibroid & 2 & 97 & 99 & $43.2 \%$ \\
Prolapse & 30 & 6 & 36 & $15.7 \%$ \\
DUB & 3 & 20 & 23 & $10.1 \%$ \\
Ovarian cysts & 1 & 20 & 21 & $9.2 \%$ \\
PMB & 3 & 17 & 20 & $8.7 \%$ \\
Endometrial hyperplasia & 1 & 16 & 17 & $7.4 \%$ \\
Endometriosis & 1 & 9 & 10 & $4.4 \%$ \\
Others & 1 & 2 & 3 & $1.3 \%$ \\
Total & 42 & 187 & 229 & 100 \\
\hline
\end{tabular}

DUB: Dysfunctional Utrine Bleeding. PMS: Post Menapousal Bleeding. 
6 (17\%). The ultrasound reports showed that in (39\%) cases there were only one fibroid, and (61\%) cases had multiple fibroids. The size of fibroid ranged from $5-17 \mathrm{~cm}$ with a mean of $(7 \pm 3.7)$.

Of those who had a vaginal hysterectomy, 20 cases (47.6\%) also had anterior/posterior repair. Tension-free vaginal tape (TVT) was applied in three (7\%) these cases.

In the abdominal approach cases, Transverse incision was used in 139 (74.4\%) cases, Midline incision in $36(19 \%)$ cases, and Maylard incision in $11(6 \%)$ cases and supraumbilical midline was used in one case $(0.5 \%)$

$7.4 \%$ was postoperative complication rate, $1.7 \%$ occurs in the vaginal hysterectomy group and $5.7 \%$ in the abdominal hysterectomy group. Although the rate is higher in the abdominal group, this difference is not statistically significant (Table 3).

Thirty-five (18.7\%) cases of the abdominal group had adhesions. Mild Adhesions were found to be in $14(7.6 \%)$ cases, moderate in $4(2.2 \%)$ cases and severe in $17(9.2 \%)$ cases. The drain was applied on $46(24.6 \%)$ of the abdominal cases. In the abdominal group, total hysterectomy was performed in 175 (93.5\%) cases and subtotal in 12 (6.5\%). One or both ovaries were preserved in $33(78.5 \%)$ of vaginal cases, and both were removed in $9(21.5 \%)$ cases. Only 59 (31.5\%) cases from the abdominal group had preserved at least one ovary, and concomitant bilateral oophorectomy was done in 128 (68.5\%) cases.

Post-operative measures including the average estimation of blood loss, from $100 \mathrm{ml}$ to $6000 \mathrm{ml}$ with a mean of $(561.5 \pm 614.4)$ and length of hospital stay after surgery are ranged from 2 to 19 days with a mean of $(4.3 \pm 2.5)$. Complications rate in both vaginal and abdominal approach are in Table 3 . However, the difference in the complications rate between both groups statistically non-significant $(P=0.7)$. Three cases were admitted to the intensive care unit from the abdominal group. Packed RBCs were transfused in 23 (12\%) cases from the abdominal group, and only two (5\%) cases from vaginal group, the difference is not statistically significant $(P=0.2)$.

Factors affecting the decision of vaginal hysterectomy for treatment of benign diseases if the age is more than 35 years ( $\mathrm{OR}=0.306 ; 95 \% \mathrm{CI}\{0.147-0.834\} ; \mathrm{P}<0.001)$. Menopause ( $\mathrm{OR}=0160 ; 95 \% \mathrm{CI}\{0.075-0.339\} ; \mathrm{P}<0.001)$ or the presenting symptoms is not vaginal bleeding $(\mathrm{OR}=0.117 ; 95 \% \mathrm{CI}\{0.052-0.260\}$; $\mathrm{P}<0.001)$, prolapsed uterus $(\mathrm{OR}=39.485 ; 95 \% \mathrm{CI}\{15.844-98.400\} ; \mathrm{P}<0.001)$, and uterine size is less than $12 \mathrm{~cm}$

Table 3. Complication.

\begin{tabular}{cccc}
\hline Complication & Vaginal (Rate) & Abdominal (Rate) & Total (Rate) \\
\hline None & $38(16.6 \%)$ & $174(76.0 \%)$ & $212(92.6 \%)$ \\
Complication & $4(1.7 \%)$ & $13(5.7 \%)$ & $17(7.4 \%)$ \\
Total & $42(18.3 \%)$ & $187(81.7 \%)$ & $229(100 \%)$ \\
Urinary complication & $2(0.9 \%)$ & $5(2.1 \%)$ & $7(3.0 \%)$ \\
Wound infection & $0(0.00 \%)$ & $6(2.6 \%)$ & $6(2.6 \%)$ \\
Thrombo-embolic & $1(0.45 \%)$ & $1(0.45 \%)$ & $2(0.9 \%)$ \\
Others & $1(0.45 \%)$ & $1(0.45 \%)$ & $2(0.9 \%)$ \\
\hline
\end{tabular}


$(\mathrm{OR}=0.770 ; 95 \%$ CI $\{0.712-0.834\} ; \mathrm{P}<0.001)($ Table 4$)$.

\section{Discussion}

The abdominal route was the most common technique used in the hysterectomy; an approach correlated with a higher rate of complications. Previous studies from Saudi Arabia [6], South Africa [8], UK and USA as reported from a 2014 systematic review showed similar finding [1].

In contrast to other studies from Germany [9], France [10], and Finland [11] more hysterectomies are performed vaginally than abdominally. Previous studies [6] [8] [9] reported that vaginal approach mainly used in patients with uterine prolapse that is similar to our results.

Ovarian preservation is common in the vaginal hysterectomy, this might be a reason

Table 4. Comparison of vaginal and abdominal hysterectomy.

\begin{tabular}{|c|c|c|c|c|}
\hline & VAGINAL & ABDOMINAL & $\begin{array}{l}\text { OR. 95\% Confidence } \\
\text { Interval }\end{array}$ & $\mathrm{P}$ \\
\hline \multicolumn{5}{|l|}{ AGE } \\
\hline LESS 35 & 12 & 106 & & \\
\hline MORE 35 & 30 & 81 & $0.306(0.147-0.834)$ & $<0.001$ \\
\hline \multicolumn{5}{|l|}{ Nationality } \\
\hline Saudi & 22 & 96 & & \\
\hline None Saudi & 20 & 91 & $1.043(0.534-2.038)$ & $<0.520$ \\
\hline \multicolumn{5}{|l|}{ Parity } \\
\hline$<4$ & 10 & 68 & & \\
\hline$>4$ & 32 & 119 & $0.647(0.253-1.181)$ & $<0.083$ \\
\hline \multicolumn{5}{|l|}{ Menopause } \\
\hline No & 11 & 129 & & \\
\hline Yes & 31 & 58 & $0.160(0.075-0.339)$ & $<0.001$ \\
\hline \multicolumn{5}{|l|}{ Past medical H } \\
\hline No & 19 & 101 & & \\
\hline Yes & 23 & 86 & $0.703(0.359-1.378)$ & $<0.195$ \\
\hline \multicolumn{5}{|l|}{ Past surgical H } \\
\hline No & 34 & 147 & & \\
\hline Yes & 8 & 40 & $1.156(0.496-2.694)$ & $<0.460$ \\
\hline \multicolumn{5}{|l|}{ Bleeding } \\
\hline Yes & 9 & 131 & & \\
\hline No & 33 & 56 & $0.117(0.052-0.260)$ & $<0.001$ \\
\hline \multicolumn{5}{|l|}{ Prolapsed } \\
\hline Yes & 29 & 10 & & \\
\hline No & 13 & 177 & $39.485(15.844-98.400)$ & $<0.001$ \\
\hline \multicolumn{5}{|l|}{ Uterine size } \\
\hline$<12$ & 42 & 141 & & \\
\hline$>12$ & 0 & 46 & $0.770(0.712-0.834)$ & $<0.001$ \\
\hline Total & 42 & 187 & & \\
\hline
\end{tabular}


to influence the selection of the route. Although the ACOG recommends that's, the vaginal route should be preferred regardless of the decision of concomitant oophorectomy [2].

Aspects that need further evaluation and adjustments for the risk of complications include the patients' age, indications for surgery. For example, primarily, the rate of complications with vaginal hysterectomy is less than that after abdominal hysterectomy in this study which might be explained by the presence of prolapse uterus which makes the operation easier, since more than ninety percent of vaginal hysterectomies are performed for patients with a prolapsed uterus. It was also reported 2014 [12].

Secondly, Wound infection was the most common complication especially reported in the abdominal group; however, this could be related to higher BMI of patients that were not calculated in this study. Further studies are highly needed to evaluate the reasons for the reluctance of gynecology surgeons in performing vaginal hysterectomy.

In a study done in Germany, operative complications were recorded in (5.5\%) cases and postoperative complications in (6\%) of cases. Operative complications included mainly urinary bladder injuries that occurred more commonly with the vaginal approach. For the postoperative complications, there was no difference between vaginal and abdominal approaches. On the other hand, a 2009 Cochrane review [1] found no difference in the rate of bladder or ureter injuries between abdominal and vaginal hysterectomies. In our study, we found the rate of urinary tract injury more common after vaginal hysterectomy and wound infection after abdominal hysterectomy. However, the difference between two groups was not statistically significant.

In a study done on the morbidity outcomes of 78,577 hysterectomies in Australia [13], complications were slightly higher after $\mathrm{VH}(9 \%)$ in comparison to $\mathrm{AH}(8 \%)$. The postoperative complication rate is similar to the present study and contradictory to a study from South Africa, were postoperative complications reported more commonly in patients undergoing $\mathrm{AH}(\mathrm{P}=0.02)$.

In our study, an estimated blood loss of $500 \mathrm{ml}$ or more was reported in 105 (56.4\%) cases with abdominal approach and in $10(23.8 \%)$ cases with the vaginal approach $(\mathrm{P}<$ 0.001). A previous Study in Saudi Arabia [6], found similar results but was not statistically significant.

The average duration of postoperative hospitalization was found to be (3.6) following $\mathrm{AH}$ and (2.4) after VH days in a recent report from Denmark [9]. In our study, the hospital stay was almost equal for both groups with no statistical significance. The average stay $10.53 \pm 5.9$ days which reported in a 2015 study [7] for hysterectomy in the management of fibroid, and length of hospital stay was shortest after VH $(\mathrm{P}<0.001)$.

In this study, thromboembolic venous events occurred in two (1.3\%) cases: one vaginal and one abdominal. This is consistent with a Cochrane meta-analysis, were there was no difference in the incidence of venous thromboembolism between $\mathrm{AH}$ and $\mathrm{VH}$.

Null parity was listed by surgeons [4], as one of the reasons to direct the choice toward the $\mathrm{AH}$. In the present study, $\mathrm{VH}$ was more familiar with patients who had the higher order of parity. 
The average age for women may also affect the method used in a hysterectomy, as reported from Italian study [14] [15]. In the present study, it was that older women undergoing $\mathrm{VH}$.

There were no mortalities recorded in association with hysterectomy for benign indications in a study done in Germany [9]. In our study, one case aged 50 years who was known to have diabetes, and hypertension died ten days following $\mathrm{AH}$ for fibroid indication. The patient had severe bleeding that could not be corrected by blood transfusion because of positive antibodies and severe transfusion reaction inducing acute renal failure. In South Africa [9] a 77-year-old overweight woman with hyper-tension developed pneumonia and died from cardiac arrest after $\mathrm{VH}$ for uterine prolapse.

We acknowledge the limitations to this study, first the population size being small to present the practice of hysterectomy in our country, further multicenter studies are needed. Second, not all hysterectomy cases included such as cases done laparoscopically.

\section{Conclusion}

Factors affecting the decision of vaginal hysterectomy for the management of benign diseases are as follows: if the age is more than 35 years or the women has reached the menopause, if they do not present with vaginal bleeding but with uterine prolapsed and if uterine size is less than $12 \mathrm{~cm}$. Vaginal hysterectomy had less postoperative complication, so we advocate that vaginal hysterectomy should be the preferred approach over the abdominal route.

\section{Conflicts of Interests}

All authors have no conflicts of interests to declare.

\section{References}

[1] Gupta, S. and Manyonda, I. (2014) Hysterectomy for Benign Gynaecological Disease. $O b$ stetrics, Gynaecology \& Reproductive Medicine, 24, 135-140. http://dx.doi.org/10.1016/j.ogrm.2014.04.002

[2] ACOG Committee Opinion No. 444: Choosing the Route of Hysterectomy for Benign Disease. Obstetrics \& Gynecology, 114, 1156-1158. http://dx.doi.org/10.1097/AOG.0b013e3181c33c72

[3] Brummer, T.H., Seppala, T.T. and Harkki, P.S. (2008) National Learning Curve for Laparoscopic Hysterectomy and Trends in Hysterectomy in Finland 2000-2005. Human Reproduction, 23, 840-845. http://dx.doi.org/10.1093/humrep/den006

[4] Butt, J.L., Jeffery, S.T. and Spuy, Z.M.V.D. (2012) An Audit of Indications and Complications Associated with Elective Hysterectomy at a Public Service Hospital in South Africa. International Journal of Gynecology \& Obstetrics, 116, 112-116. http://dx.doi.org/10.1016/j.ijgo.2011.09.026

[5] Chen, B., Ren, D.-P., Li, J.-X. and Li, C.-D. (2014) Comparison of Vaginal and Abdominal Hysterectomy: A Prospective Non-Randomized Trial. Pakistan Journal of Medical Sciences, 30, 4. http://dx.doi.org/10.12669/pjms.304.4436

[6] Sobande, A., Eskander, M., Archibong, E. and Damole, I. (2005) Elective Hysterectomy: A Clinicopathogical Review from Abha Catchment Area of Saudi Arabia. West African Jour- 
nal of Medicine, 24, No. 1.

[7] David-Montefiore, E., Rouzier, R., Chapron, C. and Darai, E. (2006) Surgical Routes and Complications of Hysterectomy for Benign Disorders: A Prospective Observational Study in French University Hospitals. Human Reproduction, 22, 260-265.

http://dx.doi.org/10.1093/humrep/del336

[8] Gu, Y., Zhu, L., Liu, A., Ma, J. and Lang, J. (2015) Analysis of Hysterectomies for Patients with Uterine Leiomyomas in China in 2010. International Journal of Gynecology \& Obstetrics, 129, 71-74. http://dx.doi.org/10.1016/j.ijgo.2014.10.031

[9] Lykke, R., Blaakær, J., Ottesen, B. and Gimbel, H. (2013) Hysterectomy in Denmark 19772011: Changes in Rate, Indications, and Hospitalization. European Journal of Obstetrics \& Gynecology and Reproductive Biology, 171, 333-338.

http://dx.doi.org/10.1016/j.ejogrb.2013.09.011

[10] Parazzini, F., Ricci, E., Bulfoni, G., Cipriani, S., Chiaffarino, F., Malvezzi, M., et al. (2014) Hysterectomy Rates for Benign Conditions Are Declining in Lombardy, Italy: 1996-2010. European Journal of Obstetrics \& Gynecology and Reproductive Biology, 178, 107-113. http://dx.doi.org/10.1016/j.ejogrb.2014.04.024

[11] Sait, K., Alkhattabi, M., Boker, A. and Alhashemi, J. (2008) Hysterectomy for Benign Conditions in a University Hospital in Saudi Arabia. Annals of Saudi Medicine, 28, 282. http://dx.doi.org/10.4103/0256-4947.51699

[12] Schollmeyer, T., Elessawy, M., Chastamouratidhs, B., Alkatout, I., Meinhold-Heerlein, I., Mettler, L., et al. (2014) Hysterectomy Trends over a 9-Year Period in an Endoscopic Teaching Center. International Journal of Gynecology \& Obstetrics, 126, 45-49. http://dx.doi.org/10.1016/j.ijgo.2013.12.017

[13] Spilsbury, K., Hammond, I., Bulsara, M. and Semmens, J. (2008) Morbidity Outcomes of 78,577 Hysterectomies for Benign Reasons over 23 Years. BJOG: An International Journal of Obstetrics \& Gynaecology, 115, 1473-1483. http://dx.doi.org/10.1111/j.1471-0528.2008.01921.x

[14] Wilczyński, M., Cieślak, J. and Malinowski, A. (2014) Supracervical Hysterectomy-The Vaginal Route. Videosurgery and Other Miniinvasive Techniques, 9, 207-212. http://dx.doi.org/10.5114/wiitm.2014.41633

[15] Zakaria, M. and Levy, B. (2011) Outpatient Vaginal Hysterectomy, Tactics from a Model Clinical Practice and Review of Perioperative Outcomes in 1162 Cases. Journal of Minimally Invasive Gynecology, 18, No. 6. 
Submit or recommend next manuscript to SCIRP and we will provide best service for you:

Accepting pre-submission inquiries through Email, Facebook, LinkedIn, Twitter, etc. A wide selection of journals (inclusive of 9 subjects, more than 200 journals)

Providing 24-hour high-quality service

User-friendly online submission system

Fair and swift peer-review system

Efficient typesetting and proofreading procedure

Display of the result of downloads and visits, as well as the number of cited articles

Maximum dissemination of your research work

Submit your manuscript at: http://papersubmission.scirp.org/

Or contact ojog@scirp.org 